\title{
Golf Training: A New Possibility to Counteract Decline in Visual-Spatial Abilities?
}

\section{Petra Jansen * and Stefanie Richter}

Faculty of Psychology, Pedagogy and Sports Science, University of Regensburg, Germany

*Corresponding author: Petra Jansen, Faculty of Psychology, Pedagogy and Sports Science, University of Regensburg, University Street 1, 93053 Regensburg, Germany, Tel: 0941943-2518; Fax: 0941943-4490; E-mail: petra.jansen@ur.de

Rec date: Nov 27, 2016; Acc date: Dec 08, 2016; Pub date: Dec 10, 2016

Copyright: (c) 2016 Jansen P. This is an open-access article distributed under the terms of the Creative Commons Attribution License, which permits unrestricted use, distribution, and reproduction in any medium, provided the original author and source are credited.

\section{Short Commentary}

It is well documented that there is a large age-related decrease in spatial performance. Older adults (63-79.5 years) showed a decrease in spatial performance independent of the kind of test, the test situation and timing conditions [1]. Especially mental rotation performance declines with age [2]. This pattern of results was also obtained with older adults who suffer from mild cognitive impairment [3] and with patients with Parkinson Disease [4]. Mental rotation is the process of imagining the representation of an object when it is turned from its original upright position [5]. Even though mental rotation is only a specific cognitive ability it is an important one, because it is helpful in everyday task like for example when someone is trying to find a way to a certain place [6].

So far, there are a lot of studies who show a relation between mental rotation performance and motor behavior. There might be a common process in mental object rotation and the programming of hand movements [7]. In a quasi-experimental study, it was shown that sports students show a better mental rotation performance than students of education science [8]. Furthermore, it was demonstrated in a study with young adults that a three-month juggling training improves mental rotation performance [9]. Also, the balance ability of the participants was related to the performance for object-based mental rotation tasks, with body figures as stimuli, in older adults [10]. Most of those studies show, that physical activity with a high amount of coordinative abilities, have a very high impact on mental rotation.

Golf is a sport, which demands a high amount of coordinative abilities like balance or eye-hand coordination and a sport, which older people like to execute. It was shown that golf training enhances the visual spatial abilities of older patients who suffer from a stroke $[11,12]$. This result is not astonishing since skilled golfers have a larger grey matter volume in brain areas which are relevant for spatial information processing, among others in a part of the intra-parietal sulcus [13], a region, which is also involved during mental rotation tasks [14]. Also, a stronger relationship of lifestyle factors with memory, but not with other cognitive functions like for example executive functions was found. Due to these preliminary positive results and the importance to counteract the decline of spatial performance in the elderly, golf training has to be regarded as a training for body, soul and mind with a high acceptance among older individuals.

\section{References}

1. Techentin C, Voyer D, Voyer S (2014) Spatial abilities and aging: A metaanalysis. Exp Aging Res 40: 395-425.

2. Jansen P, Heil M (2010) Gender differences in the mental rotation across adulthood. Exp Aging Res 36: 94-104.

3. Zapparoli L, Saetta G, De Santis C, Gandola M, Zerbi A, et al. (2016) When I am (almost) 64: The effect of normal ageing in implicit motor imagery in young elderlies. Behav Brain Res 303: 137-151.

4. Lee AC, Harris JP, Calvert JE (1998) Impairments of mental rotation in Parkinson's disease. Neuropsychologica 36: 109-114.

5. Shepard RN, Metzler J (1971) Mental rotation of three-dimensional objects. Science 191: 95-952.

6. Pazzaglia F, Moè A (2013) Cognitive styles and mental rotation ability in map learning. Cognitive Processing 14: 391-399.

7. Wohlschlaeger A, Wohlschlaeger A (1998) Mental and manual rotation. J Exp Psychol Hum Percept Perform 24: 397-412.

8. Pietsch S, Jansen P (2012) Different mental rotation performance in students of music, sports and education science. Learn Individ Differ 22: 159-163.

9. Jansen P, Titze C, Heil M (2009) The influence of juggling on mental rotation performance. Int J Sport Psychol 40: 351-359.

10. Jansen P, Kaltner S (2014) Object-based and egocentric mental rotation performance in older adults: the importance of gender differences and motor ability. Neuropsychol Dev Cogn B Aging Neuropsychol Cogn 21: 296-316.

11. Schachten T, Jansen P (2015) The effects of golf training in patients with stroke: A pilot study. International. Psychogeriatrics 27: 865-873.

12. Jansen $P$, Schachten $T$ (2016) The improvement of visual-spatial performance after golf training in patients with stroke: A pilot study. Cognition, Brain, Behavior 20: 159-169.

13. Jäncke L, Koeneke S, Hoppe A, Rominger C, Hänggi J (2009) The architecture of the golfer's brain. PloS One 4: e4785.

14. Jordan K, Heinze HJ, Lutz K, Kanowski M, Jäncke L (2001) Cortical activations during the Mental Rotation of Different Visual Objects. NeuroImage 13: 143-152. 